\title{
The effect of the type of seaward forcing on SWAN simulations at the west coast of Portugal
}

\author{
Maria João TELES ${ }^{1}$, António A. PIRES-SILVA ${ }^{2}$ \\ 1. Instituto Superior Técnico, TULisbon, Av. Rovisco Pais, 1049-001 Lisboa, Portugal. \\ mjteles@gmail.com \\ 2. Instituto Superior Técnico, TULisbon, Av. Rovisco Pais, 1049-001 Lisboa, Portugal. \\ aps@civil.ist.utl.pt
}

\begin{abstract}
:
In the present study, the SWAN model was employed to estimate the wave field on an open sandy beach at the west coast of Portugal, north of Sines Harbour. The SWAN model is a discrete spectral model based on the action balance equation and was designed to include shallow waters physics. It is the purpose of the work hereby reported to evaluate the sensitivity of the nearshore wave propagation modelling to the type of information used in the offshore boundary. For that, the SWAN model was forced with bulk parameters and with directional spectra derived from a large scale implementation of the WAM model. Wave measurements from an ADCP sensor moored in $17 \mathrm{~m}$ depth (datum), and operating during a rather stormy period, were used to model comparisons.

Verification statistics, like the bias, the root-mean-square error and the scatter index show that the significant wave height and the mean direction in the SWAN results depend on the method of specifying the incoming wave field. An improvement on the accuracy of these results is observed when directional spectra are employed to drive the coastal model.
\end{abstract}

\section{Keywords:}

Nearshore wave propagation - SWAN model - Offshore boundary conditions - Bulk parameters - Directional spectra - ADCP measurements

\section{Introduction}

In recent years, phase-averaged spectral models have been increasingly used to simulate nearshore wave propagation. They can cope with both the requirement of resolution and relatively large space domains. A variety of coastal engineering applications benefit from these characteristics, specially when complemented with phase-resolving models, including the design of coastal protection and harbour sheltering structures, the safe management of coastal resources and resorts, the evaluation of sediment transport and coastal erosion.

These regional scales applications are very often coupled with ocean basin scale wave models. In fact, the wide availability of coarse grids ocean scale wave predictions is 
rendering possible the use of their outputs as forcing conditions for the shelf/coastal scale models. This way, the incoming swell can be properly accounted. Naturally, the performance of the latter becomes dependent on the accuracy of the larger model.

In these phase-averaged models the prognostic variable is the variance spectral density, which has to be defined at the boundary. Basically, there are two ways in which this specification can be done: either the $2 \mathrm{D}$ full spectra or a set of integral parameters. In the former, the directional spectra can be estimated from field data or obtained from numerical simulations. The field measurements lack, sometimes, the temporal coverage necessary to climatologically studies and are only available at some specific sites. On the other hand, the detailed spectral information from numerical models is not archived routinely at all grid points. Only bulk parameters were available in lieu. In this case, a parametric spectrum has to be derived, typically, a 1D frequency spectrum and a directional distribution function.

The sensitivity of nearshore phase-averaged modelling to the choice of seaward forcing is investigated in this study. For that, the SWAN model was forced with bulk parameters and with directional spectra derived from a large scale implementation of the WAM model (PILAR et al., 2008). The domain of application was the west coast of Portugal, a rather exposed and energetic environment with occasionally strong swell events. The simulations were compared with ADCP observations, collected at $17 \mathrm{~m}$ depth (datum), and during a period of time with mild to rough seas.

The SWAN model (BOOIJ et al., 1999) is third-generation phase-averaged model based on a eulerian formulation of the action (variance spectral density divided by the intrinsic frequency) balance equation. It was developed aiming to deal with shallow water applications, and has evolved to include improved numerics (ROGERS et al., 2002) and physics (VAN DER WESTHUYSEN et al., 2007).

SMITH \& GRAVENS (2002) addressed the same subject of different boundary forcing with the STWAVE model used to estimate the wave field offshore North Carolina, U.S. East Coast. They specially reported the impact of the enhanced mean direction's accuracy on longshore sediment transport rate. PIRES-SILVA et al. (2002) performed a similar study at the same location which is now under investigation. The SWAN model was used with a smaller grid and in stationary mode with no wind forcing. The reader is also referred to the references therein for previous works in this open beach. ROGERS et al. (2007) pointed out inaccuracy in the directional distribution of wave energy at open boundaries as a main contributor to model errors, along with inaccuracy in the representation of wind forcing and the stationary assumption, in their wave modelling study in Southern California Bight, an area which shares some resemblances and presents almost the same sort of environmental circumstances that this stretch of the Portuguese west coast.

The organization of this paper is as follows. After this introductory section, the wave and wind data used, as well as the local morphology are described in Section 2. Section 


\section{XI $I^{\text {èes }}$ Journées Nationales Génie Côtier - Génie Civil}

Les Sables d'Olonne, 22-25 juin 2010

3 presents the numerical model, its settings and the boundary conditions. Section 4 discusses the results and the findings of the work. Conclusions are summarized in Section 5 .

\section{Wave and wind data}

The west coast of Portugal is exposed mainly to wave systems coming from the NW-WSW sector and associated with storms developed in the Atlantic Ocean with large fetches and long times of generation. This originates episodic rough weather with local wind sea and strong swell.

The nearshore wave measurements were recorded by an acoustic Doppler profile sensor (RDI Waves ADCP) moored in $17 \mathrm{~m}$ depth (datum). The experiment was conducted from January 23 to February 152001 near Pinheiro da Cruz. The most relevant feature of the bathymetry adjacent to this area is the Setubal Canyon (Figure 1).

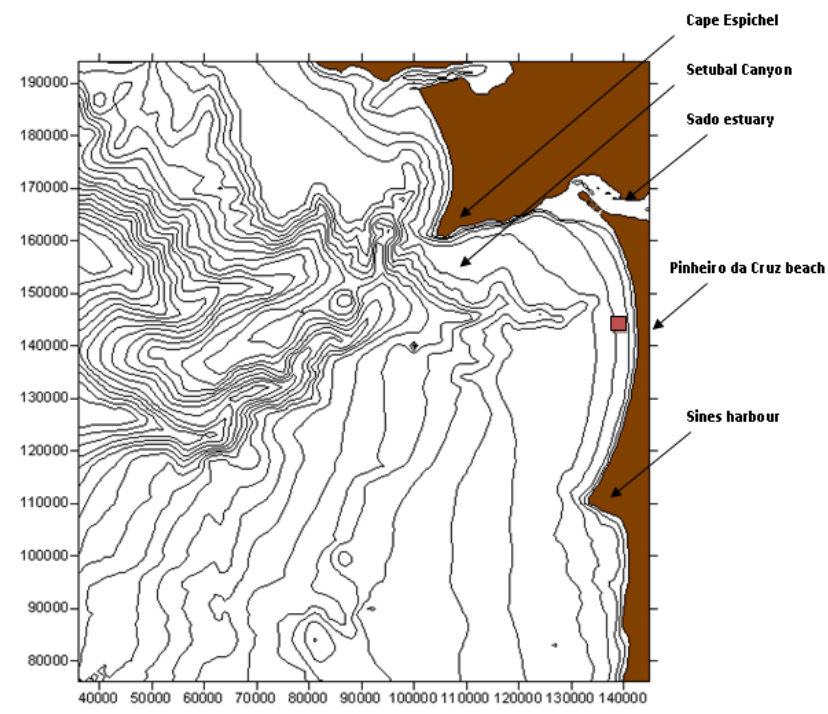

Figure 1. Bathymetry near Pinheiro da Cruz. The symbol $\square$ denotes the location of the measuring device.

Otherwise, the depth contours are fairly regular following the coast line, which is almost aligned with the N-S direction. This coastal cell is bounded by the Sado estuary to the North and the Sines Harbour to the south.

During the period of the ADCP deployment, there were two episodes where the Hs reached a maximum (PIRES-SILVA et al., 2002), at the end of January and the beginning of February. Also the wind was blowing from south-west/west in the former and from south/south-west in the latter. These episodes were associated with swell coming from North Atlantic depressions.

The wind field was obtained from the ALADIN (Aire Limitée, Adaptation dynamique, Développement InterNational) model. ALADIN is a spectral model and was run with a 
grid spacing of $12.9 \mathrm{~km}$, which correspond to 35 wave numbers and the integration domain is centered at $40^{\circ} \mathrm{N}, 9^{\circ} \mathrm{W}$. A comparison between wind forecasts and observations from the Portuguese meteorological station Sines-MC, near the Pinheiro da Cruz beach, is presented in Figure 2.
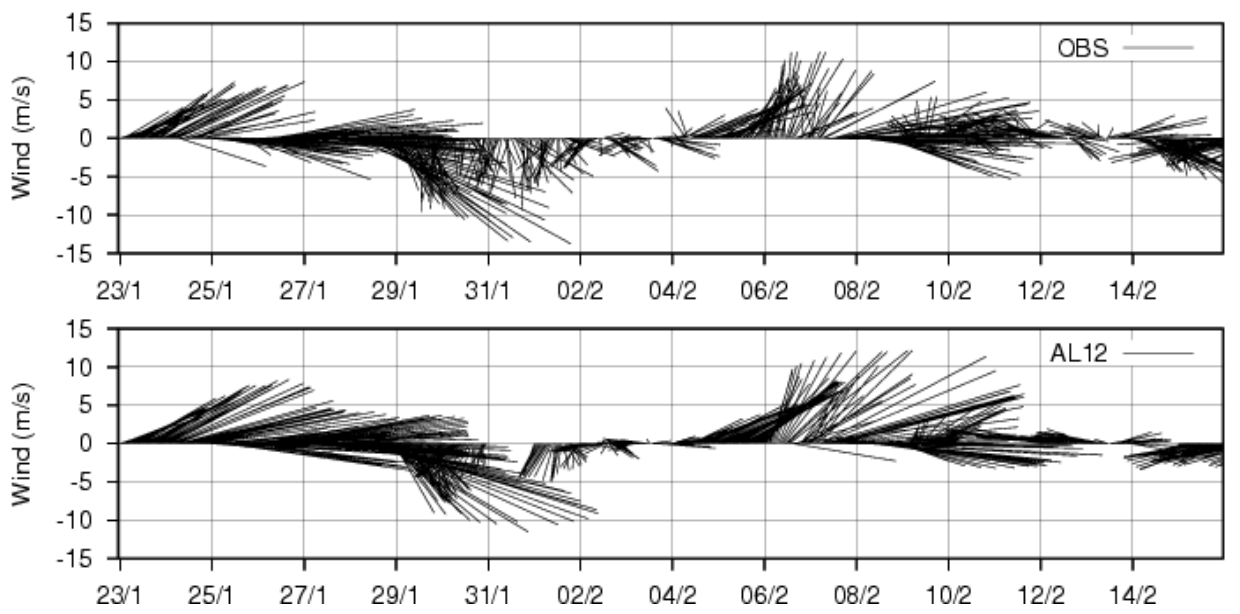

Figure 2. Time series of wind, observed and forecast for Sines-MC station. The wind direction is shown by the pointing direction of the sticks and this one is measured clockwise form the north.

\section{The wave model and boundary conditions}

SWAN (Simulating WAves Nearshore) (BOOIJ et al., 1999) is a third generation model based on the spectral action balance equation which is used to compute the wave field evolution in time and space. It includes different physical processes namely generation by wind, refraction due to currents and depth, dissipation by whitecapping, bottom friction and depth induced wave breaking and non linear wave interactions (quadruplets and triads). In the present study, the terms of non linear interactions and depth induced wave breaking were computed using the default settings in SWAN. The bottom friction dissipation was parameterized with the coefficient of swell conditions. Regarding the whitecapping dissipation mechanism, the VAN DER WESTHUYSEN et al. (2007) formulation was used. The frequency space was limited from $0.04 \mathrm{~Hz}$ to $1 \mathrm{~Hz}$ with 25 logarithmic bins and the directional space was resolved with a directional resolution of $\Delta \theta=4^{\circ}$. In what concerns the forcing with bulk parameters from the large scale implementation of WAM, a JONSWAP spectral shape (Hasselman et al., 1973) with a peak enhancement factor of $\gamma=3.3$ was scaled to these parameters and the directional spectra were input uniformly along the west open boundary.

The SWAN model was implemented with a system of three nested and regular computational grids. Because the Portuguese continental shelf is a relatively narrow strip it requires local high resolution models. Additionally, and to deal correctly both 


\section{XI $I^{\text {èes }}$ Journées Nationales Génie Côtier - Génie Civil}

Les Sables d'Olonne, 22-25 juin 2010

with the approaching NW waves and with the shadow effect of Cape Espichel (Fig. 1), the open sea boundary must be placed further offshore of this feature $(\sim 100 \mathrm{~km}$ to the coast). Table 1 presents the characteristics of these grids, also shown in Figure 3. The origin of the coordinates is referred to the Cartesian military Portuguese system of coordinates. This origin is located offshore the south west corner of Portugal. The Hydrographic Institute of the Portuguese Navy provided the bathymetry. The model was used in nonstationary mode with a variable wind field on the coarser domain and stationary conditions on the nested grids. The model time step was $5 \mathrm{~min}$.

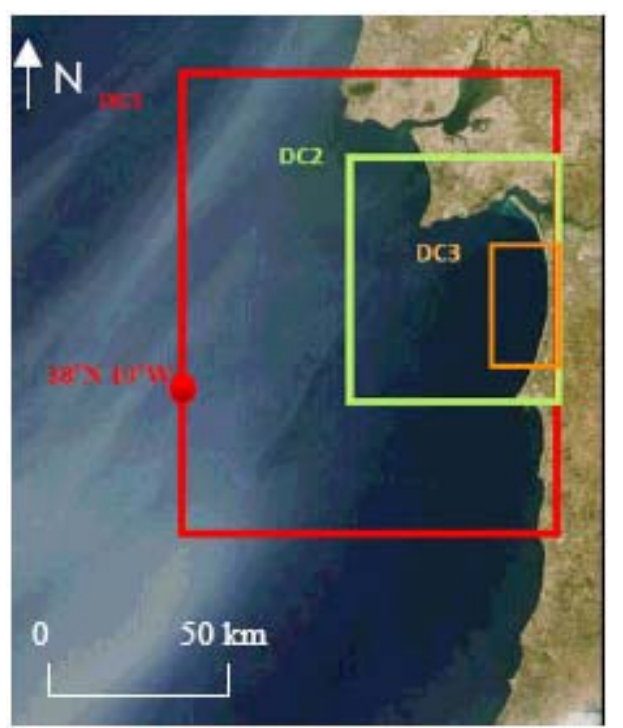

Figure 3. Schematic representation of the computational domain used in the simulations.

Table 1. Characteristics of the computational grids used in the simulations.

\begin{tabular}{llll}
\hline Domains & DC1 & DC2 & DC3 \\
\hline Coordinates (km) & $(45,25)$ & $(82,82)$ & $(124,124)$ \\
Dimensions (km) & $100 \times 170$ & $63 \times 66$ & $21 \times 29$ \\
Resolution (m) & 1000 & 500 & 100 \\
Number of grid & 13090 & 16632 & 12672 \\
\hline
\end{tabular}

\section{Results and discussions}

The statistical parameters that were used to verify the accuracy of boundary forcing were the Root Mean Square Error (RMSE), Mean Error (ME) and Scatter Index (SI), which is equal to ratio of the RMSE and the averaged value of the observations. These statistical parameters were calculated every 3 hours, from January 23 to January 30 and February 5 to February 10, 2001, the two episodes described above. The sample size was $N=55$ for the January period and $N=46$ for the February period. 
Thème 1 - Hydrodynamique côtière

Table 2. Verification statistics for the January and February period for Spectra and Integral Parameters boundary conditions

\begin{tabular}{|c|c|c|c|c|c|c|c|c|c|}
\hline & & \multicolumn{3}{|l|}{ RMSE } & \multicolumn{3}{|l|}{$M E$} & \multicolumn{2}{|l|}{$S I$} \\
\hline & & Hs (m) & $T p(s)$ & $D p\left({ }^{o}\right)$ & $H s(m)$ & $T p(s)$ & $D p\left({ }^{o}\right)$ & $H s(m)$ & $T p(s)$ \\
\hline \multirow{2}{*}{ January } & Spectra & 0.28 & 2.33 & 9.13 & 0.18 & -0.85 & -3.51 & 0.11 & 0.19 \\
\hline & $P A R$ & 0.33 & 2.64 & 9.60 & -0.15 & 1.23 & -4.10 & 0.13 & 0.22 \\
\hline \multirow{2}{*}{ February } & Spectra & 0.32 & 2.49 & 13.45 & 0.03 & -1.12 & -5.45 & 0.13 & 0.22 \\
\hline & $P A R$ & 0.60 & 2.28 & 14.03 & -0.21 & 0.18 & -1.63 & 0.23 & 0.20 \\
\hline
\end{tabular}

Generally, model simulations are in good agreement with the observations, for both periods and for each type of forcing as the low values of the SI statistics show. In particular, as it can be seen from Table 2, using 2D spectra lead to an improved fitting of $\mathrm{Hs}$ and $\mathrm{Dp}$ in comparison to a forcing with bulk parameters. The significant wave height is underestimated in the case of forcing with $2 \mathrm{D}$ spectra $(\mathrm{ME}=0.18 \mathrm{~m}$ and $\mathrm{ME}=0.03 \mathrm{~m}$ for each period, respectively) and overestimated in the other way $(\mathrm{ME}=-0.15 \mathrm{~m}$ and $\mathrm{ME}=-0.21 \mathrm{~m})$.

The peak period exhibits mixed results for the two events. Although SWAN forced by 2D consistently overestimates it and when forced by integral parameters an underestimation is registered no clear improvement is seen, contrary to what occurred with Hs and Dp.

Besides the statistical parameters calculation, time series of $\mathrm{Hs}$ and $\mathrm{Tp}$, which compare the simulations with the observation data are shown in Figures 4 and 5 for the two chosen periods.

Again, these set of figures confirm the early remarks made about the fairly good agreement between model simulations and measurements. In addition, the former follows the time evolution quite well.

\section{Conclusions}

In the present study, the SWAN model was forced with bulk parameters and with directional spectra derived from a large scale implementation of the WAM model in nonstationary mode with a variable wind field. The simulations were compared with ADCP observations, collected at $17 \mathrm{~m}$ depth (datum), and during a period of time with mild to rough seas. The experiment was conducted from January 23 to February 15 2001 near Pinheiro da Cruz.

When the 2D spectra are defined at the offshore boundary, the simulated Hs and Dp are closer to the ADCP measurements for the episodes of January and February. Notwithstanding, no such clear conclusions can be drawn in relation to the peak period. In fact, contradictory results were obtained among the two types of seaward specification. To resolve this, a different approach, with the wind field extended to the 
whole domain (but only variable in space in the stationary nested grids) is under investigation .
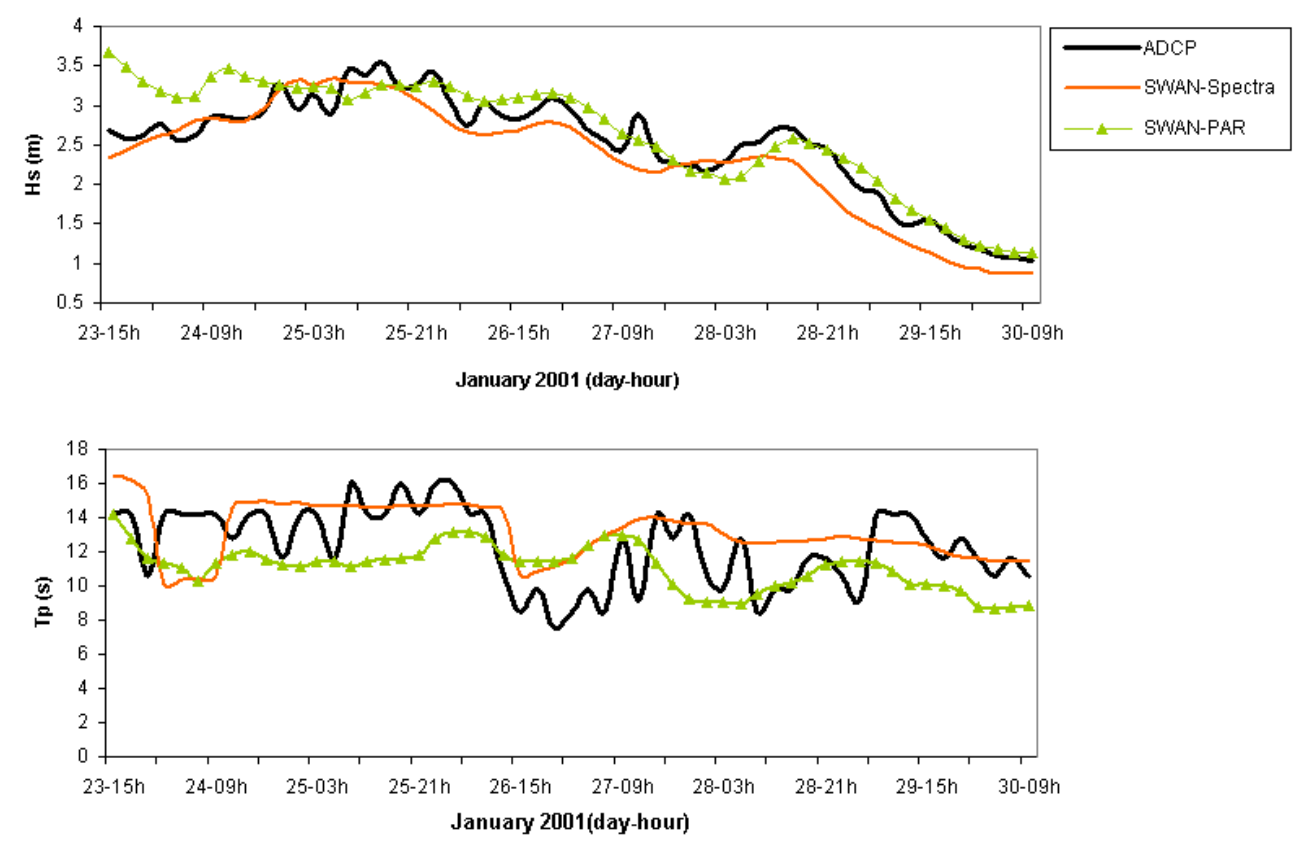

Figure 4. Significant wave height (Hs) and peak period (Tp) time series for observations and model simulations, considering the January period.
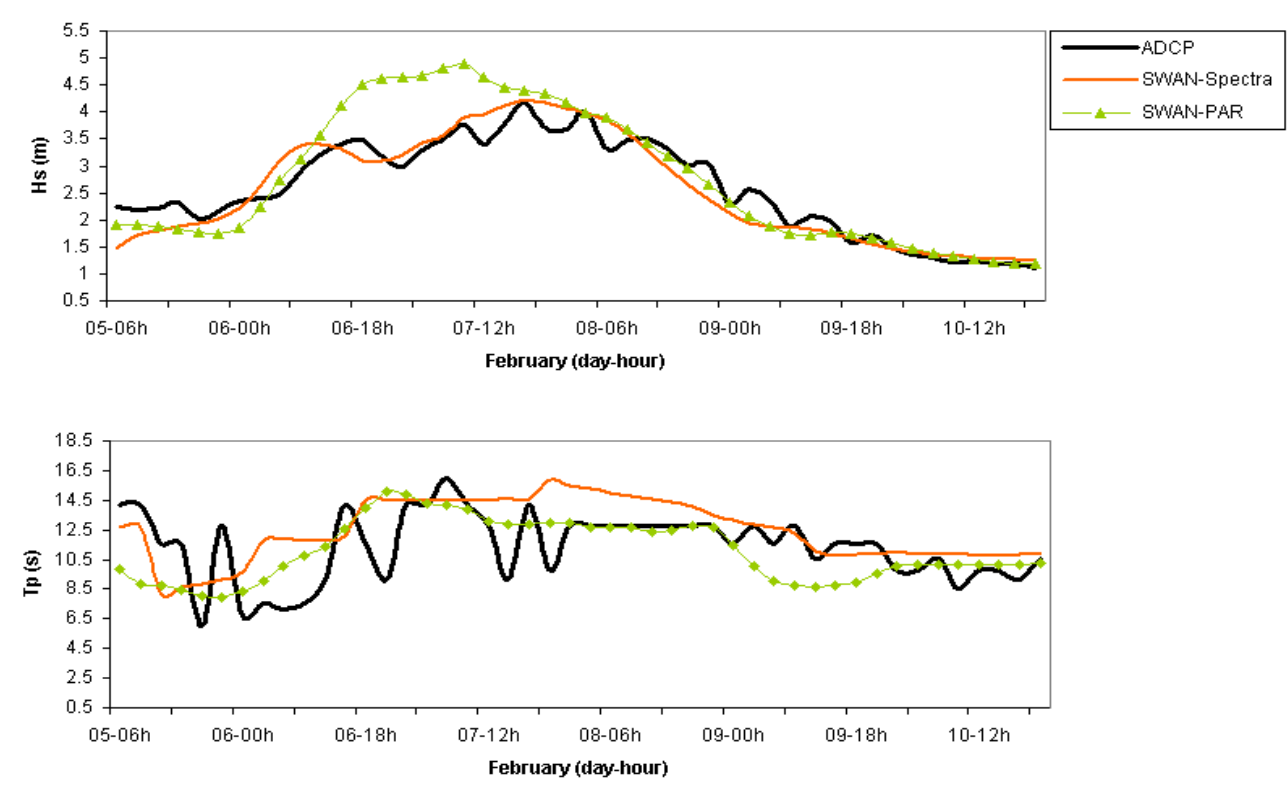

Figure 5. Significant wave height $(H s)$ and peak period $(\mathrm{Tp})$ time series for observations and model simulations, considering the February period. 
Thème 1 - Hydrodynamique côtière

\section{References}

BOOIJ N., RIS R.C., HOLTHUIJSEN L.H. (1999). A third-generation wave model for coastal regions, Part I, Model description and validation, J. Geophys. Research, 104 (C4), pp 7649-7666. doi:10.1029/98JC02622

HASSELMAN K., et al. (1973), Measurements of wind wave growth and swell decay during the Joint North Sea Wave Project (JONSWAP), Dtsch. Hydrogr. Z., 8 (A12), $95 \mathrm{p}$.

PILAR P., GUEDES-SOARES C., CARRETERO J.C. (2008). 44-year wave hindcast for the North East Atlantic European coast, Coastal Eng., 55 (11), pp 861-871. doi:10.1016/j.coastaleng.2008.02.027

PIRES-SILVA A.A., MAKARYNSKYY O., MONBALIU J., VENTURA-SOARES C., COELHO E. (2002). Wam/Swan Simulations in an Open Coast: Comparisons with $A D C P$ Measurements, Proc. $6^{\text {th }}$ Int. Symposium Littoral 2002 - The Changing Coast, Porto, pp 169-173.

ROGERS W.E., KAIHATU J.M., PETIT H.A.H., BOOIJ N., HOLTHUIJSEN L.H. (2002). Diffusion reduction in an arbitrary scale third generation wind wave model, Ocean Eng., 29, pp 1357-1390. doi:10.1016/S0029-8018(01)00080-4

ROGERS W.E., KAIHATU J.M., HSU Y.L., JENSEN R., DYKES J.D., HOLLAND K. (2007). Forecasting and hindcasting waves with the SWAN model in the Southern California Bight, Coastal Eng., 54, pp 1-15. doi:10.1016/j.coastaleng.2006.06.011

SMITH J.M., GRAVENS M.B. (2002). Incident boundary conditions for wave transformation, Proc. $7^{\text {th }}$ Int. Workshop Wave Hindcasting Forecasting, M.S.C, Banff, pp 373-384.

VAN DER WESTHUYSEN A., ZIJLEMA M., BATTJES J. (2007). Nonlinear saturation-based whitecapping dissipation in SWAN for deep and shallow water, Coastal Eng., 54, pp 151-170. doi:10.1016/j.coastaleng.2006.08.006 